\title{
ПРИЕМЫ ТЕХНОЛОГИИ РАЗВИТИЯ КРИТИЧЕСКОГО МЫШЛЕНИЯ ЧЕРЕЗ ЧТЕНИЕ И ПИСЬМО НА УРОКАХ ИНФОРМАТИКИ В 7 КЛАССЕ
}

\section{TRAINING METHODS OF TECHNOLOGY FOR THE DEVELOPMENT OF CRITICAL THINKING THROUGH READING AND WRITINGIN IN COMPUTER SCIENCE LESSONS IN THE 7TH GRADE}

\section{Petrova}

E. Vinokurova

Summary: The article presents the leading ideas, stages and training methods of technology for the development of critical thinking through reading and writing. Examples of the use of some techniques of critical thinking development technology for computer science lessons in primary school are given: INSERT, Before and After, the table "I know-I want to know-I learned", Bloom's Daisy. The technology of critical thinking in reading and writing develops students' ability to evaluate, construct knowledge, analyze text, make non-standard decisions, evaluate what is happening and their actions, develops thinking skills, creativity, nonstandard thinking.

Keywords: critical thinking, technology for the development of critical thinking, development, techniques, computer science lessons.
$\mathrm{H}$ а сегодняшний день в условиях ФГОС общего образования основные цели и задачи образования направлены на формирование и развитие личности обучающихся, на формирование их самостоятельности, на развитие творческих способностей. Таким образом, должны меняться формы организации учебной деятельности учащихся, методы и технологии обучения. Одним из таких технологий является технология развития критического мышления через чтение и письмо (РКМЧП). Все больше педагогов и учителей средней школы в своей практической работе стали применять методы и технологии формирования и развития критического мышления, в связи с тем, что сегодня на первый план выходит умение работать с информацией и проектирование учебного процесса осуществляется на основе обучения через информацию [1, 2, 3, 4]. Технология РКМЧП развивает умение учащихся работать с большим объемом информации, создавать собственное мнение на основе осмысления полученной информации; ясно, уверенно, конкретно выражать свои мысли.

Объект исследования: процесс обучения информатике в основной школе.

\author{
Петрова Валерия Петровна \\ Северо-Восточный федеральный университет \\ имени М.К. Аммосова, г. Якутск, \\ Petrova77.Ip@gmail.com \\ Винокурова Екатерина Спиридоновна \\ К.п.н., дочент, Северо-Восточный федеральный \\ университет имени М.К. Аммосова, г. Якутск,
} es.vinokurova@s-vfu.ru

Аннотация: B статье приводятся ведущие идеи, этапы и приемы технологии развития критического мышления через чтение и письмо. Исследование проведено путем изучения и анализа научно-педагогической и научно-методической литературы. Приводятся примеры некоторых приемов технологии развития критического мышления для уроков информатики в основной школе: INSERT, До и После, таблица «Знаю-Хочу узнать-Узнал», Ромашка Блума. Технология критического мышления при чтении и письме развивает у учащихся умение оценивать, конструировать знания, анализировать текст, принимать нестандартные решения, оценивать происходящее и свои поступки, развивает мыслительные навыки, креативность, нестандартность мысли.

Ключевые слова: критическое мышление, технология развития критического мышления, развитие, приемы, урок информатики.

Предмет исследования: методы и приемы развития критического мышления на уроках информатики в основной школе.

Цель исследования: изучить и проанализировать приемы развития критического мышления при чтении и письме, разработать методику формирования критического мышления на основании применения некоторых приемов РКМЧП на уроках информатики в 7 классе.

Технология РКМЧП была разработана в конце XX века в США [5] В России она стала известна с 1997 года. Сегодня она заняла прочное место среди множества образовательных технологий, является целостной общепедагогической системой, направленной на формирование навыков работы с информацией во время чтения и письма. Ее цель: развитие критического мышления с помощью интерактивного включения учащихся в образовательный процесс. Оно пригодится учащимся и в жизни, так как уметь принимать правильные решения, анализировать любую полученную информацию, обстоятельства, явления - это жизненно важные умения, исходящие из развития мыслительных навыков. 
По мнению Заир-Бек С.И. и Муштавинской И.В., «критическое мышление (как это понимается в технологии РКМЧП) - это процесс соотнесения внешней информации с имеющимися у человека знаниями, выработка решений о том, что можно принять, что необходимо дополнить, а что - отвергнуть» [5, с 5]. В работе [5] выделяется такая сторона развития критического мышления как активное действие на основе полученных знаний, которое предполагает не только собственную способность думать, но и успешную коммуникацию с другими людьми, то есть необходимость задействовать вместе с разумом эмоции и чувства, взаимоотношения. Технология критического мышления развивает такие качества, как умение самостоятельно мыслить, делать умозаключения, иметь свое мнение, выражать его, адекватно спорить, дискутировать, уважать чужое мнение, не навязывая своего, брать ответственность за собственный выбор и результаты своей деятельности.

Критичность часто свойственна человеческому мышлению. Но если в жизни она часто превращается в выискивание недостатков, в педагогике критическое мышление помогает развивать умения обучающихся объективно оценивать объект познания, трезво оценивать его положительные и отрицательные стороны, тем самым обучающиеся учатся самостоятельно конструировать знания, а не усваивать готовые. Они учатся ставить вопросы, вырабатывают аргументы и принимают продуманные нестандартные решения. То есть такое критическое мышление приносит большую пользу учащимся, так как развивает ценные мыслительные навыки, учит анализировать не только обучающий текст, но и правильно оценивать происходящее, собственные поступки.

Технологию РКМЧП можно использовать на уроках по любому предмету, в том числе по информатике. Имеется достаточное количество работ по данной технологии, например, $[1,2,3,4,5,6]$.

Рассмотрим приемы технологии РКМЧП на уроках информатики в 7 классе. Структура урока РКМЧП повторяет естественное для человека восприятие нового: сначала надо настроиться, вспомнить, что ты уже знаешь об этом, затем усвоить новое, потом подумать, где и в чем могут пригодиться полученные знания, и как их можно применить. По мнению психологов, такое природосообразное получение знания помогает его лучшему усвоению.

\section{Урок РКМЧП состоит из трех стадий:}

1. Вызов - задает тон всему уроку. Цель стадии вызова: актуализация ранее приобретенных знаний, активизация деятельности обучающихся, повышение мотивации, постановка индивидуальных целей обучающихся.

2. Осмысление. Соотнесение старой и новой ин- формации. На этой стадии происходит получение знания, его понимание и систематизация, соотнесение со старыми знаниями; осваивается способ работы с информацией, поддерживаются поставленные на этапе вызова цели.

3. Рефлексия. Выведение знания на уровень применения и понимания.

Приведем примеры приемов РКМЧП на уроках информатики. Мы выбрали данные 5 приемов, так как 4 из них предназначены для работы над текстом. Тексты по информатике, в основном, научного стиля, лишены образности, поэтому интересные способы работы над текстом помогают лучше воспринимать и усваивать текст. Это заставило нас сделать упор на приемах работы с текстом. Прием «Ромашка Блума» привлек нас необычной интересной формой контроля знаний.

1. Прием «До - После». Его можно использовать на 1 этапе (вызов) и на 3 этапе (рефлексия). Этот прием формирует умение размышлять, прогнозировать события, соотносить знакомую и незнакомую информацию, выражать свои мысли, делать сравнения, выводы. Для этого учащиеся в первой колонке «До» пишут свои предположения о теме уроке, о решении задачи. Затем, после 2 этапа урока усвоения новых знаний, заполняется вторая колонка «После», в которой отражается то новое, что узнали на уроке. Учащиеся сравнивают содержание «До и После», делают вывод (таблица 1).

\section{Таблица 1}

Прием «До-После» по теме «Текстовый редактор»

\begin{tabular}{|l|l|}
\multicolumn{1}{|c|}{ До } & \multicolumn{1}{c|}{ После } \\
\hline Тексты, набранные в компьютере & Это прикладная программа \\
\hline $\begin{array}{l}\text { Редактор журнала, газеты, кото- } \\
\text { рый редактирует тексты }\end{array}$ & $\begin{array}{l}\text { Эта программа помогает создавать } \\
\text { текстовые документы, редакти- } \\
\text { ровать их, смотреть на экране, } \\
\text { распечатывать. }\end{array}$ \\
\hline
\end{tabular}

Учащиеся наглядно видят, как изменилось их первоначальное мнение, как увеличились их знания.

2. INSERT или инсерт (I - interactive, $\mathrm{N}$ - noting, $\mathrm{S}$ system for, $\mathrm{E}$-effective, $\mathrm{R}$ - reading, $\mathrm{T}$ - thinking). Этот прием помогает с интересом усвоить текстовый материал учебника. На традиционном уроке учащимся предлагается прочитать текст и записать основные положения - сделать конспект. Благодаря методу инсерт, текст, повторяемый на уроках, становится намного интересным, а значит, и продуктивным. Им могут воспользоваться и учащиеся, и студенты, поскольку с его помощью происходит осознанная работа над текстом, его качественное усвоение. Для этого учащимся нужны чистые листы бумаги, совпадающие по размеру со страницей учебника, к примеру. Их надо приложить справа рядом с текстом (страницей учебника). Читая текст, учащиеся делают ря- 
дом на листке пометки: v+-? Пометки означают:

— «У»-уже знал;

— «+»- новое;

- «-»- думал иначе;

— «?»- не понял, есть вопросы [7].

Возможны разное количество пометок, например, 2 пометки «новое» и 1 пометка «уже знал» или каких -то пометок несколько, каких - то всего одна. После второго чтения можно вернуться к пометкам первоначального чтения, чтобы добавить что - то.

Шаг 2 приема инсерт - самостоятельное заполнение таблицы «Инсерт», количество столбцов которой соответствует количеству значков маркировки. Учащиеся записывают в четырех колонках, что они уже знали, что для них было новым, о чем они думали иначе и что не поняли по теме текста. Получается интересная, совершенно самостоятельная, индивидуальная работа над текстом.

3. Таблица Донны Угл «ЗХУ» - «Знаю, Хочу знать, Узнал». Донна Угл - профессор из Чикаго, автор стратегии «ЗХХУ (1986 г.) Эту таблицу рекомендуют использовать для сбора имеющегося материала по теме, расширения знаний по ней или систематизации. Интересный опыт использования этого приема представлен в материалах работы [8].

Этот прием близок к инсерту, его можно применять при работе над текстом параграфа, темы урока. Однако заполняется на протяжении всего урока: на стадии вызова - Знаю (опора на имеющиеся знания), на стадии осмысления - Хочу знать (цели, задача урока), на стадии рефлексии - Узнал (что узнал на данном уроке, по данной теме).

По теме «Текстовый редактор» примерный вариант использования этого приема приведен в таблице 2 .

Таблица 2

Вариант использования таблицы «ЗХУ»

\begin{tabular}{|l|l|l|}
\hline \multicolumn{1}{|c|}{3} & \multicolumn{1}{|c|}{ Х } & \multicolumn{1}{c|}{ у } \\
\hline Программы & $\begin{array}{l}\text { Текстовый } \\
\text { редактор (ТР) }\end{array}$ & TP-прикладная программа \\
\hline Символы & $\begin{array}{l}\text { Структурные } \\
\text { единицы текста }\end{array}$ & $\begin{array}{l}\text { Структурные единицы текста - сим- } \\
\text { вол, слово, строка, абзац, страница, } \\
\text { раздел }\end{array}$ \\
\hline Окно & Среда ТP & $\begin{array}{l}\text { Рабочее поле, текстовый курсор, } \\
\text { строка состояния, меню команд - } \\
\text { стандартные компоненты среды ТР }\end{array}$ \\
\hline $\begin{array}{l}\text { Курсор, шрифт, } \\
\text { формат текста }\end{array}$ & $\begin{array}{l}\text { Строка со- } \\
\text { стояния }\end{array}$ & $\begin{array}{l}\text { Строка состояния - это информация 0 } \\
\text { текущем состоянии ТР }\end{array}$ \\
\hline $\begin{array}{l}\text { Файл, печать, } \\
\text { форматиро- } \\
\text { вание }\end{array}$ & Меню & $\begin{array}{l}\text { Меню команд управления редак- } \\
\text { тором }\end{array}$ \\
\hline
\end{tabular}

\section{4. Прием «ПМИ» (Плюсы, Минусы, Интересно).}

Это прием учит анализировать, распределять, классифицировать полученную информацию. Оформляется также таблица из трех колонок. В первую колонку учащиеся записывают те факты из текста, которые могут отвечать на вопрос: «Что хорошего?» Во вторую колонку - факты, отвечающие на вопрос: «Что плохого?» И в третью колонку: «Что интересного?» Заполняя такую таблицу, учащиеся учатся точно работать с информацией, не искажая её смысла. Например, на уроке информатики по теме «Информационные процессы» можно использовать прием «ПМИ» (см. таблицу 2).

Таблица 3

Вариант использования таблицы «ПМИ»

\begin{tabular}{|c|c|c|}
\hline П (плюсы) & М (минусы) & И (интересно) \\
\hline $\begin{array}{l}\text { Внутренняя память - } \\
\text { наша память, мы } \\
\text { запоминаем разную } \\
\text { информацию ( адреса, } \\
\text { телефоны...) }\end{array}$ & $\begin{array}{l}\text { Можем забыть. } \\
\text { Информационные } \\
\text { каналы могут иметь } \\
\text { плохое качество или } \\
\text { помехи. }\end{array}$ & $\begin{array}{l}\text { Животным свойствен- } \\
\text { на память. }\end{array}$ \\
\hline
\end{tabular}

5. «Ромашка вопросов» или «Ромашка Блума» это популярный в современном образовательном мире прием, его автор - известный американский психолог и педагог Бенджамин Блум. Он состоит из вопросов, связанных с 6 уровнями познавательной деятельности: знание, понимание, применение, анализ, синтез и оценка. Шесть типов вопросов в виде шести лепестков ромашки.

1 лепесток: Знание - Простые вопросы. Это вопросы, аналогичные вопросам викторины: нужно назвать какие-то факты, вспомнить какую - либо информацию. Они часто задаются на этапе закрепления или контроля усвоения материала, на зачетах, уроках систематизации и обобщения пройдённого материала и т.д.

2 лепесток: Понимание - Уточняющие вопросы. Они задаются, чтобы уточнить прозвучавший ответ ученика или направить, подвести к правильному ответу. Очень важно эти вопросы задавать тактично, не ставя учащегося в неудобное положение.

3 лепесток: Применение - Интерпретационные (объясняющие) вопросы. Обычно начинаются со слова «Почему?», «Как можно применить ...?», «Что можно сделать из ...?» Эти вопросы отражают практическую направленность знаний, их роль в жизни человека.

4 лепесток: Анализ - Творческие вопросы. Это вопросы, ответ на которые обязательно будет содержать интерпретацию - фантазию, прогноз, предположение. Интерпретационные вопросы заставляют глубоко задумываться над вопросами, порождают неординарные широкие мысли, выходящие за рамки школьных знаний. 
Например, «Что изменилось бы в жизни, если бы вдруг не стало компьютеров?», «Как вы думаете, как будут развиваться информационные технологии?»

5 лепесток: Синтез - Оценочные вопросы. Эти вопросы направлены на выяснение критериев оценки тех или иных событий, явлений, фактов. Это могут быть творческие вопросы: «Что будет, если ...?». При этом учащиеся размышляют, как можно сравнить, сопоставить явления для их объективной оценки. Так синтез позволяет ненавязчиво, без заучивания закрепить полученные знания.

6 лепесток: Оценка - Практические вопросы: «Дайте оценку текстовым редакторам и текстовому процессору», «Назовите плюсы и минусы хранения текстов в файлах и в бумажном виде» и т.д. То есть вопросы должны подразумевать оценку, оценочные: «Как вы относитесь...?» Это самый высокий уровень познавательной деятельности, когда ученик способен дать конкретную оценку нескольким явлениям, так как для того, чтобы дать оценку, надо иметь соответственные знания, быть экспертом в данном вопросе.

Прием «Ромашка Блума», пожалуй, самый универсальный прием, который с успехом может применяться и в начальной школе. Опыт использования на уроках информатики наряду с другими приемами РКМПЧ «Ромашки вопросов» представлен в интересной авторской разработке Копыловой М.Л. «Использование технологии развития критического мышления на уроках информатики», а также в работе Стрельцовой А.Д. [9].

Форма ромашки в этом приеме близка к экологическому, природосообразному образованию, придает элемент игры контрольным вопросам по теме. Например, по теме «Текстовый редактор» можно составить следующие вопросы в виде «ромашки Блума»:

1 вопрос (простой): Что такое текстовый редактор?

2 вопрос (уточняющий): Ты сказал, что с помощью текстового редактора можно создавать текстовые документы. Правильно! Но только ли? А демонстрация через экран? А распечатка?

3 вопрос (интерпретационный, объясняющий): Почему текстовый редактор меняет название и превращается в текстовый процессор? (Это текстовый редактор с широкими возможностями форматирования текста, - включение графики, проверки правописания).

4 вопрос (творческий): Одна большая книга - один диск.

Почему с каждым годом становится больше число безбумажных изданий? (Экономия бумаги - сохранение леса).

5 вопрос (оценочный) - Что будет, если запретят компьютерные документы, безбумажные издания? (Пострадает экология)

6 вопрос (практический) -Как вы относитесь к тому, что компьютерные документы вытесняют бумажные?

Технология критического мышления развивает такие качества, как умение самостоятельно мыслить, делать умозаключения, иметь свое мнение, выражать его, адекватно спорить, дискутировать, уважать чужое мнение, не навязывая своего, брать ответственность за собственный выбор и результаты своей деятельности. Интересно заранее видеть примерный результат применения приемов технологии РКМЧП, чтобы знать, как должна выглядеть работа, на какую обратную связь от обучающегося ориентироваться. Это поможет педагогу составить критерии оценивания работ учащихся, наглядно увидеть уровень их знаний, чтобы четко знать «слабые места» учащихся и в дальнейшем помочь их преодолеть.

Таким образом, изучение возможного практического использования приемов технологии РКМЧП на уроках информатики позволило нам сделать следующие выводы:

- уроки по технологии РКМЧП отличаются от традиционных на стадии мотивации(вызова), объяснения нового материала (осмысления), подведения (рефлексии) нацеленностью на работу мысли учащихся, на самостоятельное добывание знаний. Все, что добыто своим трудом, дорого и ценно;

- приёмы, используемые в технологии РКМЧП важны для учащихся и учителей: для учащихся - направляют работу учащегося на самостоятельное и осмысленное получение новой информации; для учителей - позволяют «предвидеть» свой урок, прогнозировать его ход и результат, с интересом готовиться к уроку;

- составленные нами примерные образцы применения данных приемов развития критического мышления могут быть использованы при составлении критериев оценки работы, обучающихся на уроке.

Критическое мышление порождает актуальные на сегодняшний день качества личности как креативность, нестандартность мысли, необходимые современному человеку. Во - вторых, оно важно при чтении и письме, так как адекватное восприятие письменной информации и его грамотное изложение, умение выражать свое мнение - требование времени. 


\section{ЛИТЕРАТУРА}

1. Михайлова А.М. Развитие критического и креативного мышления на уроках с использованием ИКТ: теоретические основания и практические примеры // Информатика и образование. - 2021. -№6. -С.43-50.

2. Гребнева Д.М., Мащенко М.В. Использование приемов технологии развития критического мышления на уроках информатики в школе // Информатика в школе. -2021 . -№9. - - .27-37.

3. Болдакова И.В. Кузнецова Н.С. Развитие критического мышления в процессе обучения информатике // Педагогика. Психология. Социокинетика. - 2017. - №2. - С. 131-136.

4. Кулбаева М.М. Методические проблемы технологии развития критического мышления // Информатика в школе. - 2013. - №4. -С.50-55.

5. Заир-Бек СИ., Муштавинская И.В. Развитие критического мышления на уроке: пособие для учителей общеобразоват.учр. -2-е изд., дораб. -М.: Просвещение, 2011. -223с.

6. Пронина Н.Н. Применение технологии развития критического мышления у обучающихся в 8-9 классов на уроках информатики и ИКТ // Молодой ученый. - 2014. - №5 (64). - С. 24-26

7. Кутлыбаев К.В. Технологии развития критического мышления как способ формирования основных компетенций ФГОС // Современное образование: акутальные вопросы, достижения и инновации. Сборник статей XXXIV Международной НПК. -Пенза, Наука и просвещение, 2020. С52-53. [электронный ресурc] URL: https://www.elibrary.ru/item.asp?id=42375605

8. Свирилина К.О. Возможности технологии развития критического мышления при формировании общеучебных универсальных учебных действий // Science Time/ -2014. №7. - C.388-394. [электронный ресурc]. - URL: https://www.elibrary.ru/item.asp?id=21812740

9. Стрельцова А.Д. Использование разнообразных приемов в технологии развития критического мышления [электронный ресурс] // Форум молодых ученых. -2019. -№5(33). -C. 1196-1197. URL: https://www.elibrary.ru/download/elibrary_39242031_36015298.pdf

( П Петрова Валерия Петровна (Petrova77.Ip@gmail.com), Винокурова Екатерина Спиридоновна (es.vinokurova@s-vfu.ru).

Журнал «Современная наука: актуальные проблемы теории и практики»

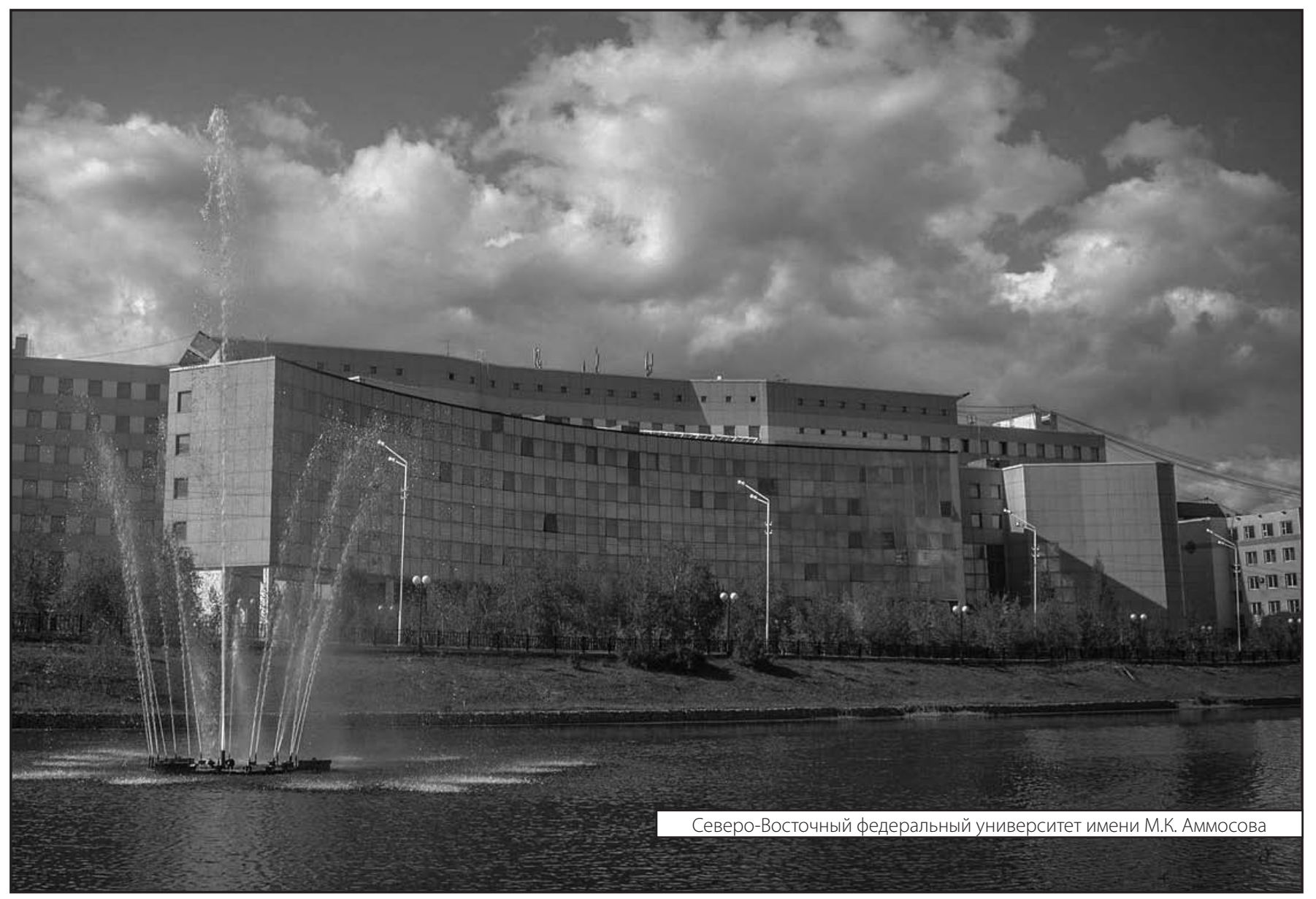

